\title{
Pregnancy in IVF cycle with a thin endometrial lining
}

\section{Ocorrência de gravidez em ciclo de fertilização in vitro com endométrio muito fino}

\author{
Ana Paula Peixoto ${ }^{1}$, Vinicius Bonato da Rosa ${ }^{1}$, José augusto Lucca Neto ${ }^{1}$, Alessandro Schuffner ${ }^{1}$ \\ ${ }^{1}$ Conceber - Centro de Reprodução Humana - Curitiba - PR \\ Accredited Redlara centre
}

\section{RESUMO}

Vários estudos demonstram a importância da espessura endometrial na taxa de sucesso de gravidez, sendo o valor de corte de $07 \mathrm{~mm}$ no dia da hCG o ideal para a maioria dos autores. No entanto, nem sempre é possível a obtenção de uma espessura endometrial ideal, havendo relatos na literatura de gestação em endométrios com espessura menor que $07 \mathrm{~mm}$.

\section{ABSTRACT}

Several studies have indicated the importance of the association of endometrial thickness with pregnancy rate. A consensus has been established that the threshold value should be $7 \mathrm{~mm}$ at the day of hCG (human chorionic gonadotrophin) injection. However, this value is not always accomplished during ovarian stimulation and there are reports in the literature of pregnancy with endometrial lining lower than $7 \mathrm{~mm}$.

\section{INTRODUCTION}

Despite all advancement in reproductive medicine, the exact mechanism how the endometrium responds to hormonal stimulation and the physiology of embryo implantation remains unknown. Studies with in vitro fertilization (IVF) cycles defined as a goal the endometrial lining thickness greater than $7 \mathrm{~mm}$ on the hCG day and/or embryo transfer. Treatments are described aiming to increase endometrial thickness such as estradiol (Demir, 2013 Check, 2011), sildenafila citrate (Viagra ${ }^{R}$ ) (Check, 2011), low doses of acetylsalicylic acid and beta blockers drugs (Demir, 2013), all with limited results. Preliminary data from a recent study (Gleicher 2013) indicated that slow infusion of granulocyte colony-stimulating factor (G-CSF) into the uterus on hCG day increased endometrial lining by $2,9 \pm 2,0 \mathrm{~mm}$ resulting in a pregnancy rate of $19,1 \%$. There is a window of opportunity during the whole menstrual cycles, when a "cross communication" between the embryo and the endometrium is observed. This event will be a key factor for the success of implantation. However, the importance of the endometrial thickness as a variable in this process is not well known. While there are no answers to this question, some clinics choose to freeze embryos and transfer them later on in a cycle with a thicker lining than transfer fresh embryos to a thin endometrium (Check, 2011, Singh 2013).

Recent studies have described molecular markers for the endometrial receptivity which makes it possible to understand the endometrial tissue and physiology before embryo transfer. This information should be a key factor to improve pregnancy rates in IVF cycles.

\section{CASE REPORT}

A 32 year old patient, with no previous pregnancy, has been followed since January 2012. The initial clinical exam revealed an ovulatory dysfunction and a male factor as possible causes for infertility. The patient presented irregular menstrual cycles that vary from 27 to 35 days with a 4 day normal menstrual flow preceded by a blood escape of 4-5 days. The male was presented with varicocele and a semen analysis indicative of a mild oligoasthenospermia. Other exams to investigate the female factor such as hormonal levels, sorology, hysterosalpingography and ultrasound mapping of endometriosis, showed no changes.

It was suggested two cycles of programmed intercourse with ovulation induction preceded by recombinant FSH (rFSH). Follicular growth was observed in all cycles with an endometrial thickness below $7 \mathrm{~mm}(5,2$ and $6,5 \mathrm{~mm}$ respectively) in the periovulatory period. There was no further increase in thickness during the post-ovulatory period with or without use of hCG to follicle rupture.

Due to presence of a thin endometrium lining in the previous cycles, it was indicated a hysteroscopy before the onset of a new treatment. An endometritis was identified and treated with doxycycline at $100 \mathrm{mg}$ every $12 \mathrm{~h}$ for 7 days. After this treatment, a third programmed intercourse cycle was attempt again with rFSH. An adequate follicular growth was achieved, however, the endometrial lining remained thin reaching $6,2 \mathrm{~mm}$ on the periovulatory period. In this last cycle, there were three follicles in the right ovary with ovulation potential $(19,17$ and $17 \mathrm{~mm}$ ) and the endometrium presented a trilaminar pattern.

In August 2012, a new cycle was initiated and this time intrauterine insemination (IUI) was attempted. Once again rFSH was used for follicle growth but endometrial thickness again did not reach $7 \mathrm{~mm}(6,2 \mathrm{~mm})$ during periovulatory period. The patient decided not to perform the insemination in this cycle since that endometrial thickness remained thin and a single ovulation was expected. She received then only with hCG for a programmed intercourse. In September 2012 it was performed IUI in a cycle stimulated by rFSH that had an adequate follicular growth, two potential ovulatory follicles and endometrial thickness of $7 \mathrm{~mm}$ during periovulatory period. The concentration of motile sperm to perform IUI was 17,7 million.

After another negative result, it was decided to attempt a new cycle of IUI (November 2012). For this cycle, the same induction protocol used in the previous cycles was repeated ( $\mathrm{FSSH}-150 \mathrm{UI}, 08$ days), however, the treatment lasted longer than previous ones and resulted in the growth of several follicles in both ovaries. Due to the number of follicles presented, it was decided to change the cycle from IUI to IVF. Twelve follicles on the right ovary and five on the left one were aspirated, but the endometrial thickness during the ultrasound exam previously de follicular aspiration reached $5,8 \mathrm{~mm}$. A total of 10 oocytes were collected and 8 of them in metaphase II. IVF was performed and 6 embryos were produced but only 2 of them reached the blastocyst stage. These two embryos were transferred and resulted in a positive pregnancy. In
Recebido em 25-05-2013

Aceito em 14-08-2013
Copyright - Todos os direitos reservados a

SBRA - Sociedade Brasileira de Reprodução Assistida 
January 2013 a single gestation was confirmed with heart beat detected by an ultrasound examination.

\section{CONCLUSION}

Several unknown factors are involved in the process leading to pregnancy. Science, with all its limitations, have been trying to maximize the chances of success by investigating the best ovulatory response to hormonal stimulation, proliferation of a better endometrium with appropriate shape and thickness and better selection of gametes and embryos. It is not rare to have cycles where all these factors are controlled except the endometrial one. In many cases there is no reason to have a thin endometrial lining, which does not respond to any hormonal treatment that stimulates its growth. At this moment there is no explanation for this observation and the thin endometrial lining should be considered a normal characteristic for that patient. How this finding is in fact interfering with pregnancy outcome? The clinician has no option when facing these cases other than eliminating all possible factors that might contribute to a decrease in endometrial quality such as endometritis, uterine synechia, polyps, hormonal disfunctions and treat them when presented.
Corresponding Author

Alessandro Schuffner

Clínica Conceber - Centro de reprodução humana

Av. República Argentina, $210 / 17^{\circ}$ andar

CEP: 80240-210 - Curitiba - PR

E-mail: alessandro@clinicaconceber.com.br

\section{REFERENCES}

Demir B ET AL. Estradiol supplementation in intracytoplasmatic sperm injection cycles with thin endometrium. Gynecol Endocrinol. 2013;29:42-5.

Check JH. The importance of sonographic endometrial parameters in influencing success following embryo transfer in the modern era and therapeutic options-part 1: the importance of late proliferative phase endometrial thickness. Clin Exp Obstet Gynecol 2011;38:197-200.

Gleicher N. et al. A pilot cohort study of granulocyte colony-stimulating factor in the treatment of unresponsive thin endometrium resistant to standard therapies. Hum Reprod. 2013;28:172-7.

Singh $\mathrm{N}$ et al. Predictive value of endometrial thickness, pattern and sub-endometrial blood flows on the day of hCG by 2D Doppler in in-vitro fertilization cycles: A prospective clinical study from a terciary care unit. Hum Reprod Sci 2011;4:29-33. 